\title{
Normativity as a Social Resource on Facebook
}

\author{
ANDREAS STÆHR \& LIVA HYTTEL-SØRENSEN
}

This article investigates how children and youth in Denmark orient toward different norms for language use in their interactional practices on Facebook. In the general public debate in Denmark, chat, texting, and social network sites such as Facebook are often blamed for causing linguistic decay and leading to impoverished spelling abilities. But to what extent are claims such as these justifiable? This is investigated in the present article through an examination of the linguistic practices of two groups of grade school pupils in a linguistically and culturally diverse environment in Copenhagen. Through our analyses we show that the participants in the study orient toward a range of different linguistic norms in their Facebook interactions, both official standard norms and unofficial peer norms. Thus, the paper argues for the presence of polycentric normativity processes in the media practices of the participants. 